\title{
Las cifras del progreso. El Departamento del Valle del Cauca según el Boletín de Estadística de 1917*
}

Artículo recibido: 27-04-2016/ Artículo modificado: 14-6-2016/Artículo aceptado: 7-7-2016

\section{Julieth Batero Portilla}

Docente contratista del Departamento de Historia de la Universidad del Valle. Licenciada en Historia y estudiante de la Maestría en Historia de la misma institución. Correo electrónico: juliethbatero@gmail.com

Referencia para citar este artículo: Batero, Julieth. "Las cifras del progreso. El departamento del Valle delCauca según el Boletín Estadístico de 1917”. Historia y Espacio 47 (2016): 67-94.

\footnotetext{
* Artículo Tipo 1: de investigación científica según clasificación de Colciencias. Este artículo hace parte del proyecto titulado “Las Condiciones de la producción agropecuaria en el Valle del Cauca:tecnología,política, producción y actores 1910-1950” (Código 4338), financiado por Vicerrectoría de Investigaciones de la Universidad del Valle y dirigido por el Dr. Hugues Sánchez Mejía.
} 


\section{Las cifras del progreso. El Departamento del Valle del Cauca según el Boletín de Estadística (1917)}

Resumen: Con la creación del departamento del Valle del Cauca en el año de 1910, la elite local responsable de la dirección de la nueva entidad territorial - propugnó por el fortalecimiento de diversas instituciones políticas y económicas que permitieran el posicionamiento de la región dentro del concierto nacional. En este artículo se analizan los resultados de dichos esfuerzos en términos de la configuración de una administración eficiente, el incremento de la productividad y el mejoramiento de las condiciones sociales de los pobladores. El análisis se hace a partir de la información contenida en el primer Boletín de Estadística del departamento publicado en 1917. Se trata de un documento especialmente significativo dentro del proceso estudiado, que muestra cómo la dirigencia de ese momento concibió la construcción de datos fehacientes, a través de la estadística, como un insumo necesario para la toma de decisiones.

Palabras claves: Valle del Cauca, administración, estadística, economía, sociedad, política.

\section{Numbers of Progress: The Department of Valle del Cauca According to Boletín de Estadística (1917)}

Abstract: With the creation of the Department of Valle del Cauca in the year of 1910, the local elite - responsible for the management of the new territorial entity- supported the strengthening of various political and economic institutions that would allow the positioning of the region within the national concert. In this text, we analyze the results of these efforts in terms of efficient management configuration, the increase of productivity and improvement of the social conditions of the people. We do analysis based on the posted information, during 1917, the first Departmental Statistical Bulletin (Boletín de Estadística); particularly significant document within the studied process. The leadership of the period conceived the construction of evidence, through the statistics, as a necessary input to decision-making.

Keywords: Valle del Cauca, Management, Statistics, Economics, Society, Politics

\section{As cifras do progresso: o Departamento do Valle del Cauca de acordo com o Boletín de Estadística de 1917}

Resumo: Com a criação do departamento do Valle del Cauca em 1910, a elite local - responsável pela direção da nova entidade territorial - propugnou pelo fortalecimento de diferentes instituições políticas e econômicas que permitissem o posicionamento da região no concerto internacional. Neste texto, analisamos os resultados dessas iniciativas em termos da configuração de uma administração eficiente, o incremento da produtividade e o melhoramento das condições sociais dos habitantes. A análise é feita a partir da informação publicada durante 1917 no primeiro Boletín de Estadística; primeiro documento especialmente significativo no processo analisado. A classe dirigente daquele momento concebeu a construção de dados fidedignos através da estatística como um insumo necessário para tomar decisões. Palavras-chave: Valle del Cauca, Administração, Estatística, Economia, Sociedade. 


\section{Introducción}

La constitución oficial del departamento del Valle del Cauca en 1910 marcó también la definición de una elite local que asumió la responsabilidad de direccionar administrativamente el nuevo ente territorial ${ }^{1}$. Esta dirigencia local, encabezada por el gobernador de turno, arrogó como tarea inmediata la necesidad de fortalecer las diversas instituciones políticas y económicas departamentales, con el objetivo de posicionar a la nueva unidad político-administrativa regional como un territorio "pujante” ${ }^{2}$. Paralelo a la creación del Departamento, aparecieron instituciones como la Cámara de Comercio de Cali; se creó una empresa encargada de la dotación y administración del servicio eléctrico de la ciudad; y arribó el ferrocarril del Pacífico a la capital vallecaucana (1915), lo que abrió paso a la comunicación de ésta con otras localidades tal y como ocurrió, dos años más tarde, con la extensión de la vía férrea desde la ciudad de Cali hasta Palmira³

Los encargados de la administración departamental concibieron la gestión pública como una forma de promover proyectos, presupuestos y políticas tendientes al progreso de la sociedad en general ${ }^{4}$. Para la toma de sus decisiones era necesario conocer en números reales la situación social y económica de la reciente circunscripción, tal y como lo proponía la estadística, un saber en boga en la época. De esta manera lo dejaba entrever el gobernador Vicente García Córdoba para el periodo de 1916 cuando, en su mensaje anual, llamó la atención sobre la importancia de contabilizar de manera estadística las condiciones del territorio gobernado, señalando que "No puede haber buena administración ni orientación acordes con las circunstancias si no se tiene constantemente a la vista cuadros

1 Enrique Rodríguez Caporali, “La burocratización incipiente: la administración pública en Cali entre 1910 y 1940 ”, y José Darío Sáenz, "La formación de la burocracia en el Valle del Cauca entre 1910 y 1950", en Formas de modernización regional en el Suroccidente Colombiano (Cali: Universidad Icesi, 2013), 45-140.

2 Jaime Eduardo Londoño Motta, "Path dependence, instituciones y ordenanzas en la configuración del departamento del Valle, 1910-1949”, CS 8 (2011): 279-314; Aura Hurtado, “Opinión pública y formación del departamento del Valle, 1903-1910”, CS 7 (2011): 161-192 ; Luis Valdivia, Economía y espacio en el Valle del Cauca 1850-1950 (Cali: Universidad del Valle, 1992).

3 Jesús Bejarano, “El despegue cafetero. 1900-1928”, en Historia económica de Colombia, edit. por José A. Ocampo (Bogotá: Siglo XXI, 1987); Luis Ordóñez, Industrias y empresarios pioneros: Cali 1910-1945 (Cali: Universidad del Valle, 1998).

4 Salomón Kalmanovitz, “Colombia en las dos fases de globalización”, en Revista de Economía Institucional, 9: 17 (2007) 43-74. 
que patenticen en definitiva la vida del pueblo" ${ }^{5}$. Como dirigente, García Córdoba prestó apoyo al primer ejercicio sistemático de compilación de cifras relacionadas con temas como los gastos de la administración pública, las rentas, la producción pecuaria y agrícola, el movimiento comercial, la movilidad poblacional, la religión, las vías de comunicación, la salubridad, la criminalidad, entre otros aspectos.

En Colombia, hasta la expedición de la ley 63 de 1914, las aduanas de los puertos eran las únicas entidades estatales encargadas de elaborar cuadros sobre el movimiento demográfico, la instrucción pública y privada, la industria ganadera, los cultivos, el degüello y el catastro. A partir de entonces y gracias a una nueva normativa, se inició un proceso de organización y recaudo de este tipo de información proveniente de las principales ciudades del país. La mencionada ley aprobó la apertura de varias dependencias en las principales capitales del país (Bogotá, Medellín, Cali, Barranquilla), entre cuyas funciones especiales estaba la recolección, sistematización y ordenamiento de las estadísticas municipales y departamentales en todas sus esferas, información que debía ser enviada a la Oficina de Estadística Nacional. Estos datos recolectados debían, en adelante, publicarse en los llamados Boletines Departamentales de Estadística. Este tipo de publicación buscaba la divulgación, en términos cuantitativos, de las diversas dinámicas económicas y sociales de la mayoría de la población.

Para el caso de Cali, en su calidad de capital del Valle del Cauca, la Oficina de Estadística Nacional estableció una sede departamental en el mes de enero de 1915 bajo la dirección del señor Tulio Delgado y cuya función sería el compendio de cifras respecto a todos los asuntos oficiales y particulares relacionados con las ciencias estadísticas de los municipios y pueblos del nuevo ente administrativo. Dos años después, hacia 1917, salió al público el primer volumen del llamado primer Boletín de Estadística. Órgano de la oficina de Estadística Nacional en el Departamento del Valle del Cauca (en adelante Boletín de Estadística), con la síntesis de la información recolectada durante 1915 y 1916 por parte del organismo encargado de la estadística regional.

Para los editores del mencionado texto, estas cifras eran importantes por dos razones. La primera era que permitían definir las políticas públicas; la segunda, dichos números mostrarían los logros alcanzados por la administración departamental al resto del país "porque demuestra sus adelantos y riquezas, advirtiendo los avances, el estancamiento o los retrocesos, a la vez que las aptitudes y energías de sus habitantes, ya sea en el campo de las ciencias y artes industriales, como en el desempeño de funciones oficiales”. Por tanto, a partir del año de su creación -en 1915- la Oficina Departamental

5 Roberto Zawadzky, Boletín de Estadística. Órgano de la oficina de Estadística Nacional en el Departamento del Valle del Cauca. 1: 1 (Cali: Imprenta del Pacífico, 1917): 6.

6 Roberto Zawadzky, Boletín de Estadística, 3. 
de Estadística del departamento del Valle del Cauca se embarcó en un trabajo particular consistente en la realización del primer censo departamental.

El acopio de la información duro alrededor de dos años. Para esta tarea se contó con la participación de los alcaldes, registradores, funcionarios municipales y del cuerpo clerical (arzobispo de Popayán, el obispo de Cali y los párrocos locales), quienes recolectaron, adjuntaron y enviaron los distintos documentos estadísticos existentes en sus despachos a la oficina centran en Cali. Esta labor daría frutos sólo hasta el 20 de febrero de 1917, fecha en la que se imprimió en la ciudad de Cali, a cargo de la Imprenta del Pacífico y en la tipografía Minerva, el primer Boletín de Estadística, bajo la dirección del señor Roberto Zawadzky y la colaboración de los señores Alberto Rentería y Rafael Pinto, "quienes sin tener en cuenta los reducidos sueldos que devengan, trabajan 9 y 10 horas diarias, algunas veces parte de las noches y los domingos, debido al recargo de ocupaciones y su decidido interés por el buen servicio del importante ramo cuya dirección y manejo nos has confiado el Gobierno Nacional en este departamento"7.

Una vez recolectados los datos, los funcionarios agruparon y formaron la estadística de los 30 municipios existentes para la época en el Valle del $\mathrm{Cauca}^{8}$, sobre los siguientes asuntos: movimiento de población; administración pública departamental y municipal, sus rentas y gastos; religión, culto, templos y personal eclesiástico, docente y de beneficencia; censos pecuario y agrícola; consumo de ganados; catastro territorial; fábricas, empresas industriales y sus producciones; comercio interior y exterior; vías de comunicación, puentes, y vehículos de transporte; servicio de policía, correos, telégrafos, teléfonos, alumbrado y energía, aseo público, movimiento de hospitales, asilos y cárceles, entre otros aspectos. Además de lo anterior, el Boletín de Estadística contenía cifras sobre diferentes noticias y consideraciones relativas a la industria pecuaria y algunos cultivos agrícolas, "cuyo incremento de producciones y mejora de calidades con el empleo de procedimientos científicos modernos, podrá desarrollar considerablemente la exportación de sus frutos, que retornarán al país enormes cantidades de dinero" 9 .

En las siguientes líneas se analiza la información estadística consignada en el mencionado Boletín de Estadística, centrando la atención en tres ejes que abarcarían la estructura administrativa, los sectores económicos y la vida social. Primero se realiza una mirada panorámica del estado en el cual se encontraba el departamento hacia 1917 a nivel territorial, administrativo y productivo, mostrando

7 Roberto Zawadzky, Boletín de Estadística, 5.

8 Este primer informe estadístico del departamento del Valle del Cauca correspondió al bienio de 1915 y 1916, el cual recogió los datos de los municipios del Valle, que para la época correspondían a treinta: Cali, Remedios, Jamundí, Yumbo, Pavas, Vijes, Buenaventura, Naya, Palmira, Candelaria, Florida, Pradera, Buga, Cerrito, Guacarí, Yotoco, San Pedro, Tulúa, San Vicente, Bugalagrande, Zarzal, Sevilla, Roldanillo, Bolívar, Huasanó, La Unión, Versalles, Toro, Cartago y La Victoria.

9 Roberto Zawadzky, Boletín de Estadística, 3. 
cómo a solo cinco años de su creación se había instalado una infraestructura institucional eficiente. Luego se hace referencia a la sociedad y sus dinámicas en relación con el crecimiento, nivel de educación y oficios realizados por los pobladores de la región. Esto para dar cuenta de las condiciones óptimas presentadas en el Valle del Cauca, las cuales permitieron posicionarlo como uno de los cinco departamentos más prósperos en las primeras décadas del siglo XX.

\section{Configuración de una estructura político administrativa}

El departamento del Valle del Cauca nació en un contexto particular de descentralización política administrativa propiciada por el gobierno de Rafael Reyes ${ }^{10}$. Este proceso generó subdivisiones en varias entidades territoriales ya existentes, ocasionando importantes reformas a las jurisdicciones administrativas, las cuales se ajustaban también a desarrollos económicos locales ${ }^{11}$. En el caso puntual de este departamento, su creación - auspiciada por una elite local-significó la aparición de una forma estatal nueva que para el año de 1910 empezaría a dirigir las riendas de esta comarca.

En este contexto, el Decreto Ejecutivo Nacional número 940 del 16 de abril de 1910 creó el departamento del Valle del Cauca, conformado por siete provincias, treinta municipios, ciento diez corregimientos y asignándosele como capital la ciudad de Cali ${ }^{12}$. Si bien el recién creado ente territorial se estructuró administrativamente de acuerdo a la normatividad consignada en la ley 149 de 1888 , fue solo hasta el año de 1913, con la reforma de dicho estatuto y la creación de la ordenanza número 4 que se logró adoptar una estructura moderna y aparentemente eficiente. Esta disposición señalaba, entre otras cuestiones, que "los departamentos tendrán independencia para la administración de los asuntos seccionales, con las limitaciones que establece la Constitución”13. Cada departamento debía tener una Asamblea encargada de legislar los asuntos administrativos, tales como la expedición del presupuesto, los privilegios locales, los impuestos, los bienes y las rentas departamentales. Así, por medio de ordenanzas, como se señala en el artículo 100 del capítulo III, se tenía "derecho de proponer proyectos los diputados de las asambleas y el gobernador, por conducto de sus secretarios, o el respectivo director de instrucción pública” ${ }^{14}$. Estos proyectos debían ser sancionados por dicha entidad en pleno y firmados por el gobernador.

10 Enrique Rodríguez Caporali, “Ciudadanos y amigos: relaciones sociales y políticas en Cali, 1906-1930”, en Historia de Cali, Siglo XX. Tomo II, Política, editado por Gilberto Loaiza (Cali: Universidad del Valle, 2012) 128-150; Enrique Rodríguez Caporali, "La burocratización incipiente", 48-51.

11 Oscar Almario, La configuración del Valle del Cauca, Colombia, 1850-1940. Espacio,poblamiento, poder y cultura (Cali: Cecan, 1994).

12 La superficie total del departamento del Valle era de 188.160 hectáreas, de las cuales 38.712 eran utilizadas en cultivos agrícolas - representando el $21 \%$ de la superficie-, 68.598 en terrenos cercados para la ganadería -siendo esto un 36\% del total-y 80.850 en terrenos selváticos - significando el 43\% del área total-.

13 Manuel F. Robles, Ley 4 de 1913 sobre régimen político y municipal (Bogotá: Casa editorial América, 1920): 24.

14 Manuel F. Robles, Ley 4 de 1913, 32. 
Por otro lado, los temas referentes a los bienes y rentas departamentales son señalados en el capítulo VI, artículo 129 de la mencionada ley, en el que se argumentaba que "Los bienes de los departamentos, así como los de los municipios, son propiedad exclusiva, respectivamente, de cada uno de ellos, y gozan de las mismas garantías que las propiedades de los particulares" ${ }^{15}$. Así mismo, se instituyó la división provincial (Título $V$, artículo 131), que establecía que cada provincia sería "regida por un prefecto de libre nombramiento y remoción del gobernador, de quien es agente inmediato" ${ }^{16}$. Además de instituir el régimen de los municipios, donde se consignó, entre otros aspectos que "El territorio sometido a la jurisdicción del alcalde constituye con sus habitantes el distrito municipal o municipio"17 esta organización municipal tendría una dirección y un Concejo encargado de "arreglar los detalles de la administración, sin contravenir a las disposiciones de las leyes y ordenanzas"18. Dichos estatutos serían sancionados por el alcalde municipal quien, además, también se encargaría de la gestión municipal, comprendiendo todo lo relativo al ejercicio de las funciones de sus empleados y al buen manejo de éstos. Por lo tanto, "El alcalde es el jefe de la administración pública en el municipio, ejecutor de los acuerdos del concejo y agente inmediato del prefecto. El alcalde es, además, jefe superior de policía en el territorio de su jurisdicción" ${ }^{19}$. Esta disposición posibilitaba un orden administrativo jerarquizado encabezado por el Presidente de la República, seguido del Gobernador, el Prefecto Provincial y, finalmente, el Alcalde Municipal. Paralelo a estas figuras, funcionaban las Asambleas Departamentales y los Concejos Municipales.

\section{La estructura fiscal del departamento del Valle del Cauca}

Sobre el anterior esquema jurisdiccional se instaló el sistema de bienes y rentas departamentales del Valle del Cauca. Este cuerpo político y administrativo debía sostenerse con dineros provenientes del gobierno nacional, pero también con rentas propias. Por tal razón, la Asamblea debía aprobar un presupuesto anual donde se proyectaban los ingresos y egresos destinados al funcionamiento de este ente. Según las estadísticas obtenidas de los presupuestos de rentas efectivas del departamento en el periodo comprendido entre los años de 1911 a 1917 (Gráfico 1), la dirección distrital manejó,

15 Manuel F. Robles, Ley 4 de 1913, 40.

16 Manuel F. Robles, Ley 4 de 1913, 41.

17 Manuel F. Robles, Ley 4 de 1913, 43.

18 Manuel F. Robles, Ley 4 de 1913, 44.

19 Robles, Ley 4 de 1913, 54. Según el artículo 184 de la mencionada ley las atribuciones de los alcaldes eran las siguientes: 1. Cuidar de que el Concejo se reúna oportunamente y desempeñe los deberes que le corresponden; 2. Convocarlo a reuniones extraordinarias cuando un caos grave y urgente lo exija; 3 . Conceder licencias a los concejales; 4 . Suministrar al concejo los informes y datos que necesite para el buen desempeño de sus funciones; 5 . Inspeccionar con frecuencia los establecimientos públicos del municipio, para que marche con regularidad; 6. Nombrar y remover libremente los empleados de su oficina; 7 . Conceder licencia a los empleados municipales, en los casos y términos especificados por la ley; 8. Cumplir y hacer cumplir la constitución, leyes, ordenanzas, acuerdo y decretos que estén en vigor. 
organizó y recolectó sus recursos de manera eficiente: se pasó, como puede observarse, de reunir \$ 545.000 en todo el año de 1911 a $\$ 439.967$ en los meses de enero a junio de 1917, permitiendo suponer que al finalizar ese año se tendrían rentas superiores a los $\$ 800.000$ pesos.

\section{Gráfico 1. Presupuesto efectivo (en pesos) del Departamento del Valle del Cauca, 1911-1917}

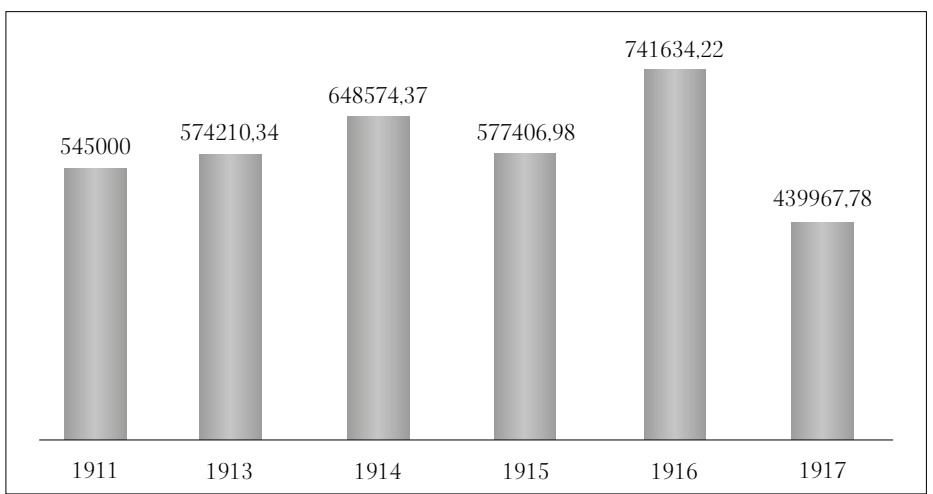

Fuente: Elaboración de la autora a partir de Cuadro de estadística comparativa de los Presupuestos de Rentas Efectivas del Departamento del Valle en los años fiscales de 1912 a 1917, en Roberto Zawadzky, Boletín de Estadística. 1: 1. Cali: Imprenta del Pacífico, 1917: 44. La cantidad del año de 1917 solo corresponden al primer semestre.

Al comparar estos ingresos con los gastos efectuados para el mismo periodo ${ }^{20}$ se observó, durante la vigencia fiscal del año 1913, cómo se obtuvieron ganancias por \$32.063, dinámica que no fue igual para los años posteriores, en los que los municipios comprometieron más de los recursos recaudados durante las vigencias de 1914 y 1915 provocando un déficit de \$209.383 y de \$ 50.760 en cada año respectivamente. No obstante esta situación cambiaría para el bienio siguiente, en el que los buenos manejos financieros lograron estabilizar los ingresos y mantenerlos hasta el año de 1917. Es así que para el primer semestre de ese año se poseía un superávit de $\$ 81.955$ pesos.

El buen manejo administrativo dado por los dirigentes departamentales permitió que, en años posteriores a 1917, el departamento se fortaleciera en el aspecto financiero, por lo que logró hacerse beneficiario de préstamos ante la banca nacional e internacional para emprender la realización de grandes obras de infraestructura que beneficiarían el desarrollo y progreso del Valle del Cauca ${ }^{21}$.

Según las cifras mostradas, el departamento estaba aumentando sus finanzas diariamente. No obstante, en este punto valdría preguntarse: ¿de dónde prevenían los recursos recibidos por la admi-

20 Esta información se obtuvo del cuadro "Presupuestos de gastos efectivos del departamento del Valle en los años fiscales de 1912 a 1917”, en Roberto Zawadzky, Boletín Estadístico, 45.

21 Enrique Rodríguez Caporali, “La burocratización incipiente”; José Darío Sáenz, "La formación de la burocracia”. 
nistración departamental? Se tiene, por un lado, la estructura de rentas departamentales (ingresos), la cual se discriminaba en los siguientes rubros: auxilio de la nación al sistema judicial, cobro de transporte fluvial, degüello de ganado vacuno, extracción de cacao, consumo de licores, peajes, registro e hipotecas (notarias), consumo de tabaco, vales de la nación, reintegros por alcances, vigencias expiradas, impuestos varios y un fondo contra la langosta. En cuanto a las finanzas recolectadas en el departamento a nombre de la nación, para los años de 1912 a 1916 arrojaron el producto líquido de $\$ 6.224 .106$, es decir, un promedio anual de \$1.244.821; ingresos que en su mayoría provenían de los recaudos obtenidos por la aduana de Buenaventura, representados en un $95 \%$, seguidos por otros menores como los correos y el papel timbrado. Los gastos demandados por esta oficina gubernamental derivaban en su mayoría del sostenimiento y mantenimiento de las instalaciones, el personal y el sistema de correos.

Con relación a los egresos del Valle del Cauca, éstos se destinaban en su mayoría al funcionamiento del aparato burocrático (gobierno, hacienda, justicia, instrucción pública y apoyo al culto católico) y la realización de obras públicas y prestación del servicio de aseo, higiene, policía, mantenimiento de vías públicas, gastos generales y pago de la deuda pública ${ }^{22}$. De los llamados gastos de funcionamiento podemos resaltar el siguiente dato: la burocracia departamental tenía a su disposición 1.818 empleados repartidos en sus 30 municipios; la mayoría de estos funcionarios se concentraban representaba en la ciudad de Cali (751 funcionarios), seguida por Buenaventura (155), Buga (141) y Palmira (138). Estos empleados públicos se dividían en tres ramas: los delegados de los servicios municipales, los encargados del servicio provincial y departamento y los comisionados encargados del ámbito nacional. Estas contrataciones representaron a nivel territorial un gasto total de \$682.309 para el año de $1916^{23}$.

Este breve esbozo de las finanzas departamentales permite afirmar que los gobernantes vallecaucanos, para el periodo estudiado, estaban preocupados por el buen manejo de los recursos, siendo esta labor efectiva pues, como se ha señalado, se recolectaron fondos suficientes para asumir las erogaciones que presentaba el nuevo pero "pujante" ente territorial.

\section{El sector productivo departamental}

Las informaciones y cifras relacionadas con la economía departamental fueron importantes y bien detallados en el Boletín de Estadística. Éstos incluían el número de hectáreas cultivadas, el almacenamiento pecuario, los talleres fabriles, el comercio y las principales ocupaciones de los habitan-

22 Roberto Zawadzky, Boletín de Estadística, 44-45

23 Roberto Zawadzky, Boletín de Estadística, 46 
tes. En general se observa una inquietud relevante por cuantificar las actividades ligadas al sector mercantil, sobre todo como insumo para el establecimiento de políticas de desarrollo y crecimiento. Además de eso, los números muestran el impacto ocurrido sobre el comercio de mercancías por la apertura del canal de Panamá y la conexión del ferrocarril del Pacífico con el puerto de Buenaventura. Es decir, son compendios que muestran un tímido crecimiento financiero, propiciado por la vinculación de Colombia a los mercados mundiales y en especial del Valle del Cauca con el llamado eje cafetero y el puerto de Buenaventura.

Tenemos entonces que la estructura de rentas de la provincia para el año de 1917 era liderada por el sector agropecuario, seguido por el comercio de mercancías por Buenaventura y un incipiente desarrollo fabril. Estos sectores con características y engranajes diferentes, como se observará a continuación, lograron jalonar el crecimiento económico de una de las regiones del sur occidente colombiano ${ }^{24}$.

\section{El sector agrícola}

Como se ha mencionado, el departamento del Valle del Cauca poseía un número total de 188.160 hectáreas, de las cuales 10.685 se ocupaban del cultivo de cacao, 8.000 en la siembra de caña de azúcar, 6.000 al cultivo de maíz, 604 de café y 4.300 de plátano, mientras que 68.598 hectáreas se utilizaban en la cría de ganado vacuno, repartidas entre pastos naturales y artificiales ${ }^{25}$. La selva y el llamado “monte bajo" y “montañas altas" ocupaban 80.850 hectáreas del total general. Las anteriores cifras dan cuenta que, para la segunda década del siglo XX, la orientación de la economía local era hacía la ganadería.

Los productos agrícolas que más áreas de cultivo poseían eran la caña de azúcar y el cacao. Por lo anterior, el Boletín de Estadística realizó un resumen de los productos más relevantes, en el que se incluía su crecimiento y las expectativas que se tenían a nivel regional. De esta manera, se buscaba motivar a los cultivadores y empresarios a invertir en su siembra y producción. El resultado es que varios funcionarios empezaron a cuestionarse sobre si la producción agrícola era suficiente y plantearon la necesidad de fortalecimiento de dicho sector mediante políticas públicas ${ }^{26}$.

En lo que respecta al cultivo del cacao, el mismo Boletín de Estadística ofrece un panorama de la cantidad de plantas sembradas en el departamento. Se señala que existían 4.274 .000 árboles cacaoteros cargadores, cuya producción anual ascendía a 1.148.900 kilos de cacao. Sin embargo, se espe-

24 Albeiro Valencia Llanos, Colonización, fundaciones y conflictos agrarios. (Gran Caldas y Norte del Valle) (Manizales: Artes gráficas Tizan: 2000); Alonso Valencia Llanos, Empresarios y políticos en el Estado Soberano del Cauca (Cali: Universidad del Valle: 1993).

25 Adriana Santos Delgado y Hugues Sánchez Mejía, La irrupción del capitalismo agrario en el Valle del Cauca: políticas estatales, trabajo y tecnología, 1900-1950 (Cali: Universidad del Valle, 2010).

26 Jesús Bejarano, “El despegue cafetero. 1900-1928”, 173-207. 
cificaba que la productividad no era mayor debido al poco interés de los cultivadores en sus plantaciones, lo que ocasionaba el desperdicio y la disminución de la cosecha, calculada en 3.851.100 kilogramos, lo que representa en valor monetario la suma de $\$ 770.000 .00$ oro. En consonancia con lo anterior, se aconsejaba fomentar el cultivo "científico de las plantaciones" e invertir en el cuidado de los terrenos y los fertilizantes, lo que redundaría en un rendimiento más óptimo:

Con gastos relativamente pequeños, que están al alcance de los propietarios de cacaotales, que les rembolsarán con creces las cosechas abundantes posteriores al cultivo y abono de las tierras, como vamos a demostrarlo con cálculos sobre 100 árboles cargadores cuya producción normal por año son 20 quintales que vale $\$ 400$ oro: el rendimiento actual es la cuarta parte; pérdida evidente de \$300. El cultivo moderno de la misma plantación, inclusive el valor del abono incorporado al pie de los árboles, no excede de $\$ 0.30$ oro cada uno; en las dos cosechas del año siguiente rendirán los 1000 cacaoteros 20 quintales y en los cincos años siguientes cinco veces más, lo que representa $\$ 2.000$ oro; deducidos \$ 500 que cuesta el cultivo, abono artificial y cuidado de la plantación en dicho tiempo, resalta un beneficio total de $\$ 1.500$ o sean $\$ 0,30$ oro por árbol. ${ }^{27}$

Otro de los productos publicitados para la expansión de su cultivo era la siembra de la caña de azúcar. Según el Censo Agrícola del departamento del Valle del Cauca, consignado en el Boletín de Estadística, hacia el año de 1916 se cultivaban 8.000 hectáreas de caña de azúcar, produciendo un total de 19.550.000 kilogramos de dulce repartidos en un promedio anual de 2.470 kilogramos de caña de azúcar por hectárea cultivada. La distribución de esta cantidad se daba de la siguiente manera: 5.250.000 kilogramos de azúcar, 10.300 .000 de panela y 4.000.000 de mieles cuyo destino eran las fábricas de licores. Así mismo, se exportaban 600.000 kilogramos de azúcar y 3.368 de panela, por valor de 48.430 pesos oro, y el resto de la producción se consumió en los abastos locales.

Lo anterior muestra cómo el panorama del sector productivo azucarero se mostraba ideal para la producción a gran escala de panela de excelente calidad, la cual se exportaba a otra región, (especialmente al Eje Cafetero), lo que generaba $\$ 1.760 .000$ oro y un beneficio líquido de $\$ 640.000$ oro, según los cálculos del Boletín de Estadística. Se recomendaba entonces a los agricultores y productores, fijar su mirada en el cultivo de la caña de azúcar, señalando que la inversión de capital era poca y sus ganancias grandes, además de la demanda de dulce cada vez más alta a nivel mundial:

Los agricultores del Valle del Cauca pueden ensanchar paulatinamente la producción del dulce, sin necesidad de emplear por ahora fuertes capitales para establecer grandes ingenios, aumentando sus actuales cultivos de caña a medida que lo indique la demanda y

27 Roberto Zawadzky, Boletín Estadístico, 70 . 
precios del artículo en los mercados extranjeros, poniendo en actividad muchos molinos de fuerza hidráulica y animal que hace mucho tiempo no funcionan, debido a que la producción del dulce ha superado los consumos locales, impidiendo distintos inconvenientes la exportación de los sobrantes de azúcar y panela. ${ }^{28}$

Estos dos cultivos, el de cacao y caña de azúcar, tuvieron un énfasis permanente a lo largo de la edición del Boletín de Estadística. No obstante, también se encontraron otros productos que se valoraron por su alto cultivo y producción, aportando no sólo al consumo local, sino también a la economía de exportación. Estas dinámicas permiten observar como en el Valle del Cauca para el año de 1915, se sembraban con café 5.604 hectáreas, equivalentes en árboles a 11.208.000 de los cuales se obtuvieron 4.500,000 kilos divididos 2.240,000 kilogramos para el consumo local y 1.218,320 kilogramos para exportación, lo que producía ganancias por valor de $\$ 304,580$ oro $^{29}$.

Dentro de los cultivos de producción extensa encontramos el maíz, que durante el período estudiado contaba con 6.000 hectáreas cosechadas, produciendo 14.716,000 kilogramos en 1915 y 12.000,000 kilogramos el año siguiente. Esta disminución de un periodo a otro se presentó debido a un largo verano, lo que impidió abastecer el mercado local e hizo necesario recurrir a la importación de 900,000 kilogramos. En cuanto al cultivo de plátano, en el Censo agrícola del Valle de $1915^{30}$ se señala que ese año se dio una producción de 34.704.000 kilogramos, sembrados en 4.300 hectáreas con un total de 2.150.000 árboles. Esta tendencia se sostuvo durante el 1916, en el que, a pasar del aumento del consumo, también incrementó la producción a un monto de 43.000,000 kg.

De manera general, se observó que para los inicios del siglo XX, no era la caña de azúcar la predominante del paisaje agrícola regional. Este producto estaba, en número de hectáreas, detrás de la producción de cacao y competía con el maíz, el plátano y el café. Se debería esperar más de una década para iniciar el despegue azucarero y la instalación de ingenios, procesos importantes en la región a la hora de abordar la producción de azúcar refinada en Colombia ${ }^{31}$.

\section{El sector fabril}

Dentro del contexto nacional, el departamento del Valle del Cauca vivió un despegue moderado en la constitución de industrias de bienes manufacturados de consumo y de talleres industriales. Es decir, su industrialización fue tardía si se compara con las ciudades de Bogotá, Medellín y Barranqui-

\footnotetext{
28 Roberto Zawadzky, Boletín Estadístico, 101.

29 Roberto Zawadzky, Boletín Estadístico, 67-69.

30 Documento que se menciona en Roberto Zawadzky, Boletín Estadístico, 69.

31 Hugues Sánchez Mejía y Adriana Santos, “Estado, innovación y expansión de la agroindustria azucarera en el valle del río Cauca (Colombia), 1910-1945”, en Revista América Latina en la Historia Económica. 21: 3 (2014) 201-230.
} 
$11 a^{32}$. Entre los factores que favorecieron este incipiente desarrollo industrial se pueden mencionar los siguientes: la política de fomento industrial iniciada tímidamente por el gobierno de Reyes, la economía en tránsito hacia la industrialización, los recursos líquidos captados por los bancos que empezaron a funcionar en Cali a comienzos del siglo, la inversión en la construcción del ferrocarril de El Pacífico, la llamada carretera central y el muelle de Buenaventura y, esencialmente, la demanda de productos manufacturados ${ }^{33}$.

Para el año de 1917, la región contaba con 357 establecimientos repartidos entre fábricas y talleres artesanales (Tabla 1). Es necesario aclarar que la inclusión de los talleres artesanales como fábricas dentro del Boletín Departamental de Estadística del Valle del Cauca elevaba el número de fábricas. Un ejemplo de esta situación se percibió al discriminar las empresas industriales de la provincia de Cali por la utilización de energía ya fuese eléctrica, a vapor o hidráulica, obteniendo de esto solo 17 fábricas y no 61 como lo señaló el censo; las 44 entidades restantes, sumando la mayoría, hacían uso de fuerza humana y animal. La ciudad de Cali concentraba el número más alto de talleres industriales impulsados por energía eléctrica o a vapor, donde se fabricaban cigarrillos, pastas alimenticias, jabones, curtiembres, hielo y se trillaba café, entre otros. Seguían luego las ciudades de Palmira, Tuluá y Buga, agrupándose en estas provincias las actividades relacionadas con la caña de azúcar, en el que se encontraban los molinos produciendo panela, un poco de azúcar y unos cuantos más fabricaban licores.

32 Jairo Henry Arroyo, Historia de las prácticas empresariales en el Valle del Cauca (Cali: Universidad del Valle, 2006); José Antonio Ocampo, "El surgimiento de Cali como centro industrial", en Crisis mundial, protección e industrialización, edi. José Antonio Ocampo y Santiago Montenegro (Bogotá: Grupo editorial Norma, 2007).

33 Luis Valdivia, Economía y espacio en el Valle del Cauca 1850-1950; Carlos Ramírez, "El camino férreo del Pacífico 1862-1915" (Tesis de pregrado en Historia, Universidad del Valle, 2009). 
Tabla 1. Relación de fábricas y productores industriales

\begin{tabular}{|c|c|c|c|c|c|}
\hline \multirow{2}{*}{ Provincias } & \multirow{2}{*}{ Relación de fábricas y producciones industriales } & \multicolumn{4}{|c|}{ Número de fábricas } \\
\hline & & Energía $^{1}$ & Animal & Fuerza Humana & Total \\
\hline \multirow{21}{*}{ Cali } & Bujias esteáricas & .. &. & 2 & 2 \\
\hline & Baldocines Para Piso & .. & .. & 2 & 2 \\
\hline & Bebidas Gaseosas & .. & .. & 3 & 3 \\
\hline & Chocolates & .. & $\ddot{1}$ & .. & 1 \\
\hline & Cigarrillos & 3 & .. & 1 & 4 \\
\hline & Cigarros & 1 & .. & 11 & 12 \\
\hline & Cervezas & .. & .. & 3 & 3 \\
\hline & Ropa interior para hombre & 1 & .. & .. & 1 \\
\hline & fósforos cerilla & 1 &. & .. & 1 \\
\hline & Harina de maíz & .. & .. & 1 & 1 \\
\hline & Idem de trigo & 1 & .. & .. & 1 \\
\hline & Idem de plátano &. & .. & 1 & 1 \\
\hline & Hielo & $\ddot{2}$ & .. &. & 2 \\
\hline & Jabón para lavar & 2 & .. & 1 & 3 \\
\hline & chircales (adobes, ladrillos y tejas) &. & .. & 10 & 10 \\
\hline & Tenerías & 2 & .. & .. & 2 \\
\hline & Trilladoras de café & 4 & .. & .. & 4 \\
\hline & Tostaderas y molino de café & .. & .. & 3 & 3 \\
\hline & Pastas de harina para sopa & .. & .. & 2 & 2 \\
\hline & Panela (molino de caña) & & 3 & & 3 \\
\hline & Total Provincia de Cali & 17 & 4 & 40 & 61 \\
\hline \multirow{3}{*}{ B/ventura } & Bebidas gaseosas & .. & .. & 1 & 1 \\
\hline & Fábrica de velas & .. & .. & 1 & 1 \\
\hline & Total Provincia de Buenaventura & 0 & 0 & 2 & 2 \\
\hline \multirow{8}{*}{ Palmira } & Azúcar (molido de caña) & 1 & 3 & .. & 4 \\
\hline & Cervezas & .. & .. & 2 & 2 \\
\hline & Cigarrillos & .. & .. & 3 & 3 \\
\hline & Cigarros & .. & .. & 6 & 6 \\
\hline & Chircales (adoves, tejas, ladrillos) & .. & .. & 4 & 4 \\
\hline & Licores (aguardientes, alcohol, ron, etc.) & 1 & .. & .. & 1 \\
\hline & Panela (molidos de caña) & 6 & 30 & ... & 36 \\
\hline & Total Provincia de Palmira & 8 & 33 & 15 & 56 \\
\hline \multirow{7}{*}{ Buga } & Cervezas & .. & .. & 1 & 1 \\
\hline & Cigarrillos & .. & .. & 1 & 1 \\
\hline & Cigarros &.. &.. & 3 & 3 \\
\hline & Chircales (adoves, ladrillos, etc.) & .. & .. & 2 & 2 \\
\hline & Licores (resacado, ron, alcohol, etc.) & 1 & .. & 1 &.. \\
\hline & Panela (molinos de caña) & 4 & 26 & .. & 30 \\
\hline & Total Provincia de Buga & 5 & 26 & 8 & 37 \\
\hline \multirow{8}{*}{ Tuluá } & Bebidas Gaseosas & .. & .. & 1 & 1 \\
\hline & Cervezas Inferiores & .. & .. & 2 & 2 \\
\hline & Cigarrillos (inferiores) & .. & .. & 1 & 1 \\
\hline & Cigarros & .. & .. & 8 & 8 \\
\hline & Chircales (adoves, telas, etc.) & .. & .. & 2 & 2 \\
\hline & Licores (aguardiente, alcohol, etc.) & $\ddot{1}$ & $\begin{array}{l}. . \\
. .\end{array}$ & 1 & .. \\
\hline & Panela, Azúcar (molinos de caña) & 3 & 28 & .. & 31 \\
\hline & Total Provincia de Tuluá & 4 & 28 & 15 & 45 \\
\hline \multirow{5}{*}{ Roldanillo } & Cigarros & .. & .. & 3 & 3 \\
\hline & Chircales (adoves, telas, etc.) & .. & .. & 2 & 2 \\
\hline & Panela (molinos de caña) & .. & .. & 20 & 20 \\
\hline & Sombrero de paja, esteras, etc. & .. & .. & 5 & 5 \\
\hline & Total Provincia de Roldanillo & 0 & 0 & 30 & 30 \\
\hline
\end{tabular}




\begin{tabular}{|l|l|c|c|c|c|}
\hline \multirow{5}{*}{ Cartago } & Alfombras de lana (para montura) &.. &.. & 2 & 2 \\
& Cervezas (inferiores) &.. &.. & 1 & 1 \\
& cigarrillos (inferiores) &.. &.. & 30 & 1 \\
& Cigarros (comunes) &.. &.. & 30 \\
& Chircales (adoves, telas, ladrillos) &.. &.. & 2 & 2 \\
& Panela (molino de caña) &.. & 10 &.. & 10 \\
& Lazos, guambías y alpargatas de fique &.. &.. & 20 & 20 \\
& Loza de barro fina &.. &.. & 60 & 60 \\
\cline { 2 - 6 } & \multicolumn{1}{|c|}{ Total Provincia de Cartago } & $\mathbf{0}$ & $\mathbf{1 0}$ & $\mathbf{1 1 6}$ & $\mathbf{1 2 6}$ \\
\hline
\end{tabular}

Fuente: Roberto Zawadzky, Boletín de Estadística. 1: 1. Cali: Imprenta del Pacífico, 1917: 87.

En lo referente al uso de fuerza humana, los talleres usaban ésta en gran cantidad, siendo su principal motor de producción. Dichos establecimientos fabricaban una variedad importante de manufacturas, dentro de las que se encontraban velas, cigarrillos, cigarros, pastas, bebidas gaseosas, elaboración de adobes, ladrillos y tejas para la construcción. La provincia de Cartago ocupaba el primer lugar en la utilización de este tipo de energía, con un total de 116 establecimiento encargados de la elaboración de productos tales como las losas de barro fina, los lazos, guambías, alpargatas de fique y las alfombras de lana.

La Tabla 1 también posibilita señalar que ya se empezaba a definir, aunque de manera precaria, el despegue industrial en la región, siendo Cali su epicentro. Varios factores incidieron en este crecimiento: la apertura del canal de Panamá, la construcción de infraestructuras, la creación de condiciones institucionales y el diseño de políticas públicas que permitieron en los años posteriores un fluido desarrollo departamental ${ }^{34}$.

\section{Sector comercial}

Varios factores coincidieron en el crecimiento del sector comercial en el Valle del Cauca. Por un lado, la demanda externa de café y su buen precio en el mercado de New York, lo que dinamizó los mercados locales en los que se producía este grano, seguido del progreso poblacional y al aumento de los ingresos en el campo, elementos que incentivaron el comercio interno. Cali como ciudad capital se articuló rápidamente al famoso triángulo de oro (Medellín, Cali y Bogotá), la zona de más desarrollo económico en Colombia durante la primera mitad del siglo XX y la cual recibió la mayor inversión estatal. Las cifras consignadas en el Boletín de Estadística sobre el tema comercial posibilitan inferir las dinámicas de producción del naciente campo empresarial regional, que incluyen construcción de viviendas, producción de textiles, alimentos y bebidas, artes gráficas, prensa, cigarrillos y velas, confecciones de calzado y jabones, entre otras. De esta forma, se posicionaron una serie de sectores industriales en la región con grandes signos de productividad provocando, por un lado, una impor-

34 Luis Valdivia, Economía y espacio en el Valle del Cauca 1850-1950, 134. 
tante acumulación de capital y, por otro, un proceso de modernización urbana ${ }^{35}$. Este impulso mercantil trajo consigo la expansión comercial en el departamento y la apertura sus mercados internos y de exportación (Gráfico 2), observándose la relación existente de cuatro ejes: producción, consumo, importación y exportación, factores trascendentales a la hora de expandir la movilidad comercial del departamento.

En el Gráfico 2 se observan las dinámicas comerciales que presentó el departamento durante el periodo 1915-1916 a nivel monetario, en el que se aprecia cómo la producción local aumentó de un año a otro en un total de $\$ 1.628 .691$ pesos oro, pasando de $\$ 10.767 .666$ en 1915 a $\$ 12.396 .357$ en 1916, en tanto el consumo creció en \$ 829.876 oro, pasando de 10.908 .661 en el año de 1915 a 11.738.537 en 1916. Un dato importante fueron las importaciones, las cuales disminuyeron, pasando de \$1.832.269 en 1915 a \$ 1.524 .429 en 1916, mientras que las exportaciones crecieron en \$ 606.719. Estas cifras dan cuenta también de varios fenómenos ocurridos a nivel departamental; con la apertura del ferrocarril del Pacífico en 1916, las cifras de exportación empezaron a aumentar, si se comparan con las del periodo anterior. Además, la producción local fue de la mano con el consumo registrado, lo que permitió que el mercado interno cubriera en su gran mayoría la demanda local, lo que exigió menos importaciones.

\section{Gráfico 2. Estadística del comercio (en pesos) en el Departamento del Valle (1915-1916)}

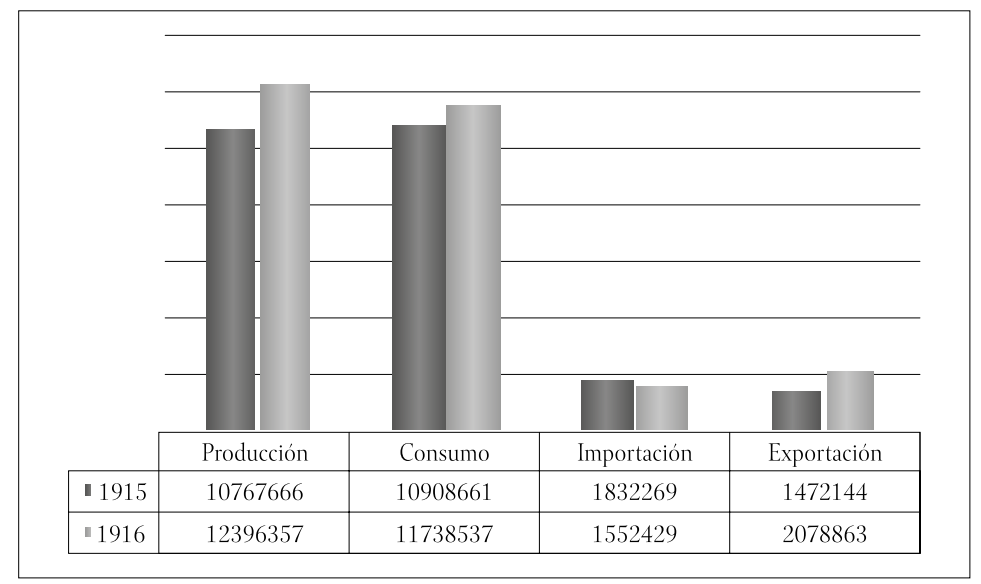

Fuente: Elaboración de la autora a partir de los cuadros de estadística del comercio interior del departamento del Valle en 1915 y 1916, en Roberto Zawadzky, Boletín de Estadística. 1: 1. Cali: Imprenta del Pacífico, 1917: 67-68. 
Así mismo, el departamento exhibió un crecimiento significativo en los cuatro ejes analizados. Estos números representaron la producción local de tipo agrícola, pasando de 95.637.066 kg en 1915 a $104.192 .800 \mathrm{~kg}$ en 1916, representados en productos tales como: azúcar, arroz, almidón, bujías, cacao, café, carne vacuna y porcina, vísceras, fideos, fique, frutas varias, frijoles y garbanzos, harina de maíz, jabón de lavar, queso, legumbres y hortalizas, maíz, mantequilla, manteca, miel, panela, papa y otras raíces, piel vacuna, plátano y tabaco. Por el lado de la producción de sustancias líquidas, la cual se medía por botellas, tenemos que para el año de 1915 se produjeron 20.951 .534 botellas, aumentando su producción a 22.213.927 en el año de 1916, este sector estaba representado en productos como aguardiente, alcohol, ron, leche, alcohol exportable y cerveza.

Por último, se tiene la producción por millares la cual se concentró en la elaboración de cigarros, cigarrillos, fósforos, huevos y aves de corral, lo que representó 372.460 millares para 1915, suma que creció al doble para el periodo de 1916, cuando se producen 637.000 millares en todo el departamento. Los niveles de producción aumentaron de acuerdo a las necesidades que se tenían por abastecer a un número más amplio de población que requería alimentos, bebidas y productos para la subsistencia básica. Además, los discursos de los dirigentes y la prensa local hacían énfasis en que si se quería llevar la prosperidad a todo el territorio debía darse un aumento de la producción agropecuaria e industrial para llevarla a mercados externos, ya sean regionales o de otros países.

Para dinamizar los mercados debió existir un consumo que impulsará la producción, como sucedió en el caso regional, donde se presentó un aumento en el consumo de los productos agropecuarios y manufacturados locales. Se observa entonces que, para el periodo de 1915, en el territorio vallecaucano se consumían $103.312 .783 \mathrm{~kg}$ de los productos arribas mencionados, cifra que disminuyó a $2.215 .783 \mathrm{~kg}$ para el año siguiente. Los líquidos, por ejemplo, aumentaron de 21.291.918 litros a 22.495.130 litros de los años de 1915 a 1916.

Por otro lado como para la época la producción local no cubría la demanda de ciertos productos, fue necesario la importación de 7.446 .999 pesos oro entre kilos, botellas y millares para el año de 1915, correspondientes a productos tales como: arroz, licores y vinos, bujías varias, cigarrillos, fósforos, frijoles y garbanzos, harina de trigo, jabón de lavar, maíz, papa y otras raíces y sal. Sin embargo este panorama cambió hacia 1916, puesto que la balanza comercial presentó un cuadro particular, se dio un incremento de la producción local y una disminución del consumo de productos importados. Por ello, durante 1916 se importaron 3.864.332 entre kilos, botellas y millares, discriminados en productos como arroz, licores, bujías, fideos, harina de trigo, sal, tabaco, anís y cerveza.

Con este panorama, el Valle del Cauca equilibraba su balanza comercial. Por una parte, producía para abastecer a sus pobladores e intentaba mantener bajo los niveles de importación y, por otro, 
empezaba a comercializar sus excedentes. Esto se observó cuando se analizaron los niveles de exportación que tuvo el departamento para el bienio de 1915 a 1916, donde envió principalmente a Estados Unidos una cuantía de 4.191.373 kilogramos dentro de los que se encontraban artículos como: azúcar, cacao, café, frutos varios (naranja, piña, limones y níspero), jabones para lavar y pieles vacunas, además de 51.120 millares entre cigarrillos y fique. Aumentando sus envíos en 1.926 .795 kilogramos para 1916, representados en 6.000.288 kilogramos y 169.000 en millares de los productos antes señalados ${ }^{36}$.

\section{El sector pecuario}

En los inicios del siglo XX, la ganadería era una actividad muy difundida por todo el territorio colombiano, siendo sin duda una industria sobresaliente, tanto en los valles calientes como en las frescas tierras altas. Colombia durante la primera mitad del siglo XX era el cuarto país productor de ganado vacuno en América Latina $^{37}$. Las principales regiones donde se realiza esta actividad eran la zona alta del río Sinú en el departamento del Bolívar, el valle del río Cauca, el valle del río Magdalena, los Llanos Orientales y el valle del río Patía en la región de Nariño. También se encontraba ganado en las regiones altas de la sabana de Bogotá y Boyacá38. En lo que respecta al Valle del Cauca, para el periodo estudiado, se contaba con un surtido de 679.404 cabezas, discriminado principalmente entre ganado vacuno, caballar y porcino, cuyo valor comercial ascendía a los $\$ 14.422 .520$ pesos oro (Gráfico 3 ).

\section{Gráfico 3. Censo Pecuario del Valle del Cauca (1916)}

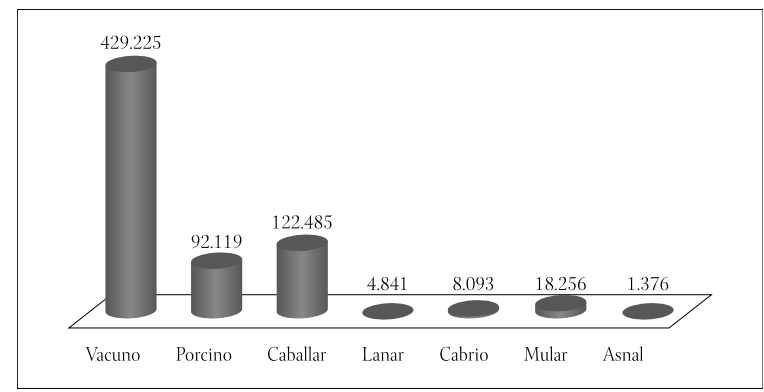

Fuente: Elaboración de la autora a partir de Censo pecuario de 1916. Roberto Zawadzky, Boletín de Estadística. 1: 1. Cali: Imprenta del Pacífico, 1917: 76.

\footnotetext{
36 Esta información se obtuvo de los cuadros estadísticos del comercio interior del departamento del Valle en 1915 y 1916 , en Roberto Zawadzky, Boletín de Estadística, 67-68.

37 Alberto Flórez-Malagón. El poder de la carne. Historia de ganaderías en la primera mitad del siglo XX en Colombia (Bogotá: Universidad Javeriana: 2008) 164.

38 Salomón Kalmanovitz y Enrique López, La agricultura colombiana en el siglo XX (Bogotá: Fondo de cultura económica, 2006) 286
} 
Si a lo anterior se le suma la cantidad de terreno ocupado por esta actividad en el departamento, se tiene que un 36\% del área total de éste era utilizado para la actividad ganadera. De esta producción pecuaria, se puede observar que el Valle del Cauca para el año de 1915 consumía, entre ganado vacuno y porcino, un total de 59.948 cabezas, cifra que se incrementaría para el año siguiente en 66.690 cabezas, mostrando una diferencia de 6.742 entre año y año. Se percibe así cómo empezaba a crecer la demanda de carne en el territorio departamental, lo que también señala un crecimiento considerable de la población.

Este incremento en materia de producción y demanda de ganado pudo reflejarse en una cifra mayor; influyó en esto el hecho que los ganaderos creían que los censaban para cobrarles más impuestos, por lo que declaraban solo una parte de stock. Por tal razón, las cantidades declaradas a los alcaldes y corregidores en algunos casos solo representó la mitad o incluso la tercera parte de lo que poseían. Con esta información se pudo calcular la presencia de ganado vacuno en la región, el cual excedía las 900.000 cabezas. En cuanto al consumo, según lo señalo el Boletín de Estadística:

En el cuatrienio de 1913 a 1916 se consumieron en los 30 municipios del Valle 85.877 reses vacunas machos: multiplicando este guarismo por 5 , conforme la práctica antioqueña.... que queda explicada, resultan 429.383 animales: en el mismo tiempo se sacrificaron 50.540 vacas y como también deben existir 10 grupos de igual número de hembras, de 1 a 10 años de edad, o sean 505.400, resulta un total de 938.925 cabezas vacunas, que aproximadamente es la existencia en todo el Departamento, a fines de 1916, deduciendo las 136.417 consumidas en dicho año. ${ }^{39}$

La cita anterior muestra que el creciente consumo de ganado vacuno y porcino en el departamento se relacionó con una demanda constante de proteína animal y sus derivados, por parte de una población en aumento que requería una mejor alimentación ${ }^{40}$. El Boletín de Estadística consideró y calculó esta situación de la siguiente manera:

cada res vacuna macho rinde 25 kilogramos de carne, menudos y grasas potables, cada hembra 175 ídem y cada marrano 65 kilos, por lo que se obtiene que para 1916 el ganado sacrificado arroja un total de 9.771 .750 kilos de carne. Ahora calculando un promedio de consumo anual de 36 kilos, resultan 271.370 habitantes en el Valle; o sean más de 40.000 sobre el censo oficial de 1912 con el acrecimiento natural hasta fines de 1916 y la inmigración considerable de individuos y familias de otros Departamentos y países. ${ }^{41}$

39 Roberto Zawadzky, Boletín de Estadística, 76.

40 Marcela Calera, "Historia de los precios de los alimentos en Cali según el diario El Relator, 1919-1950" (Tesis de pregrado, Universidad del Valle, 2013).

41 Roberto Zawadzky, Boletín de Estadística, 22. 
Las ciudades en las que se consumía mayor cantidad de carne eran Tuluá, Buga, Cartago, Palmira y Cali, siendo las dos últimas las más representativas con porcentajes de 23\% y 35\% respectivamente. Estas cifras muestran cómo empezaba el proceso migratorio de la población a las principales cabeceras municipales del departamento, aspecto que se amplía en el siguiente punto.

\section{La sociedad}

Las estadísticas sobre la sociedad vallecaucana en el Boletín de Estadística son abundantes. En sus páginas aparecen aspectos como el crecimiento demográfico, y cuestiones de ámbitos privados como la religión, las prácticas sacramentales, la fe, la ocupación, las enfermedades, entre otros temas. Con estos datos se puede observar cómo la población total del departamento creció en un período de cuatro años al 14\%. A partir de la realización del censo de 1912, cuando la población existente se calculaba en 285.000 habitantes, aumentó aproximadamente 10.500 pobladores por año; alcanzando para el año de 1916 una población calculada en 300.000 habitantes. ${ }^{42}$

La información recogida en el periodo abordado ayudó a caracterizar los movimientos de la población con relación a nacimientos, matrimonios y defunciones (Gráfico 4). Según los cuadernos parroquiales, durante el periodo comprendido entre 1912 y 1916, en los diferentes municipios del Valle del Cauca se dieron 37.578 nacimientos, 4.726 matrimonios y 19.327 defunciones. De los nacimientos predominaron los varones (19.083), seguido por las mujeres (18.495), para un total de 37.578 nacimientos, de los cuales el 54\% fueron legítimos y los 46\% restantes se registraron como hijos naturales, es decir, nacidos fuera del matrimonio o no reconocidos por el padre.

\footnotetext{
42 Roberto Zawadzky, Boletín Estadístico, 8. Estas cifras no son del todo exactas, puesto que la recolección de estos datos se dio por parte de los párrocos y alcaldes municipales a vuelta de correo, ya fuese vía cartas o telégrafo que hacían llegar a la ciudad de Cali. Esto posibilitó múltiples errores dado que, por un lado, la mayoría de la población vivía en las zonas rurales y no tenían ningún tipo de registro y, por otro lado, cuando se promulgaban los registros parroquiales sólo se hacía constancia de los actos oficiados como bautismos, matrimonios y defunciones, lo que excluía a una parte de la sociedad que no hacia parte de la fe cristiana o no tenía las condiciones económicas para pagar estos servicios.
} 


\section{Gráfico 4. Movimiento de población en el Valle del Cauca 1912-1916}

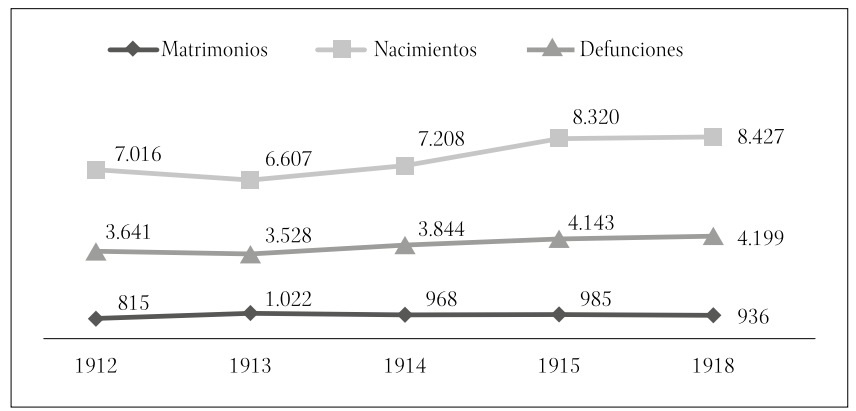

Fuente: Elaboración de la autora a partir de Resumen de movimiento de población del Departamento en el decurso de 1912 a 1916. Roberto Zawadzky, Boletín de Estadística. 1: 1. Cali: Imprenta del Pacífico, 1917: 12.

Llama la atención la manera de clasificar en el censo a los infantes en cuatro categorías raciales, dando como resultado dicha tipificación el nacimiento de 2.568 niños blancos, 228 indígenas, 964 negros y 3072 mezclados. La primacía de los nacimientos de niños "mezclados" da cuenta de las relaciones sociales que se esteban fijando entre diversos actores, así como la tendencia de la sociedad a romper las barreras de color. La provincia que mayor nacimientos presentó para el año de 1916 fue Cali, con 609 infantes registrados, seguida de forma descendente por Palmira con 420, Buga 419, Tuluá y Roldanillo ambas con 386 nacimientos cada una, Cartago 218 y por ultimo Buenaventura con tan solo 125 infantes nacidos. Aunque el registro de nacimientos múltiples es poco para este mismo periodo se registraron en el departamento un total de 54 casos, de los cuales 29 correspondieron a varones y 25 a mujeres. Con esto se logró calcular que de cada 1.000 nacimientos, 508 fueron varones y 492 mujeres, predominando el sexo masculino. Sin embargo, cuando se compara esto con la tasa de defunciones para ese mismo periodo se presenta que en los varones fueron más propensos a fallecer; es así que de cada 1.000 muertes 539 fueron varones y 461 mujeres.

Sobre las causas de mortalidad infantil las enfermedades más frecuentes entre los niños de $0 \mathrm{a}$ 5 años fueron la viruela con un total de 57 infantes fallecidos, seguida por la tosferina con 80 niños, las lombrices con 130, la diarrea con 194 y la bronquitis con 219 niños muertos por esta causa. Pese a lo anterior, las sumas más altas la encontramos en la falta de cuidados higiénicos y un grupo de enfermedades que se aglutinaban como no definidas, representando para el periodo de 1916 respectivamente 238 y 248 niños muertos en todo el departamento, una cifra bastante alta ${ }^{43}$. 
Este registro de movimiento de la población es importante porque muestra las condiciones de los habitantes no solo del departamento sino del país, lo que obligaba a los órganos gubernamentales a tomar medidas para mejorar la calidad de vida de éstos. Así se manifiesta en el Boletín de Estadística:

El registro completo del movimiento de población es sin duda el más necesario benéfico servicio que presta la Estadística oficial a la sociedad, porque manifiesta con números exactos la mortalidad pública y sus causas, con separación de sexos y edades. Estas informaciones con de vital importancia para el país, principalmente para los progresos y observaciones de la ciencia médica. ${ }^{44}$

\section{Instrucción Pública}

Además de lo anterior, los registros demográficos permiten saber más acerca de sus pobladores. Datos como profesión y nivel de alfabetización dan un panorama de los niveles educativos y las medidas tomadas para mejorarlos. Se observa entonces que en 1916 la mayoría de la población era rural, y se ocupaba en actividades correspondientes a la agricultura en el caso de los hombres y a los oficios domésticos en el caso de las mujeres, con poco acceso al sector educativo. Esta falencia debía ser solucionada, ya que si se quería prosperar y desarrollar todo un panorama productivo se necesitaba personal con preparación académica y profesional, fundamentales para el impulso del crecimiento económico regional.

Esta necesidad de formación permitió “un proyecto de transformación y modernización”, estrechamente relacionado con el desarrollo productivo departamental. Dicho proyecto regional fue impulsado por algunos dirigentes políticos, empresarios (comerciantes e industriales), la iglesia, entre otros agentes influyentes de la provincia, que conformaron parte de una elite en construcción. Estos estamentos eran conscientes de que no bastaba con ampliar las tierras cultivadas y administrar una nueva economía con los instrumentos que tenían a su alcance; se necesitaba también invertir en educación de calidad ${ }^{45}$.

Con esta obligación se implementó un aparato educativo en el Valle del Cauca; para 1916 ya se contaba con un total de 320 escuelas entre primaria y secundaria, públicas y privadas (Tabla 2), en las cuales estudiaban 25.888 alumnos de ambos sexos, dirigidos por 619 maestros entre los que se encontraban directores (a), subdirectores (a), hermanos Maristas, hermanas de La Caridad y madres Belentinas y Franciscanas.

\footnotetext{
44 Roberto Zawadzky, Boletín de Estadística, 22.

45 Maritza Guachetá, "Historia de la educación pública en el Valle del Cauca 1912-1915: Instrucción primaria y secundaria" (Tesis de pregrado en Historia, Universidad del Valle, 2013).
} 
Tabla 2. Estadística de instrucción en el Valle del Cauca 1916

\begin{tabular}{|c|c|c|c|c|c|c|c|c|}
\hline \multirow{3}{*}{ Provincia } & \multicolumn{5}{|c|}{ Escuelas primarias } & \multicolumn{3}{|c|}{ Escuela secundaria } \\
\hline & \multirow{2}{*}{$\begin{array}{c}\text { Alumnos } \\
\text { Matriculados }\end{array}$} & \multicolumn{2}{|c|}{ Oficial } & \multicolumn{2}{|c|}{ Particular } & \multirow{2}{*}{$\begin{array}{c}\text { Alumnos } \\
\text { Matriculados }\end{array}$} & \multirow{2}{*}{ Oficial } & \multirow{2}{*}{$\begin{array}{l}\text { Particu } \\
\quad \text { lar }\end{array}$} \\
\hline & & Urbana & Rural & Urbana & Rural & & & \\
\hline Cali & 6694 & 31 & 28 & 7 & 7 & 927 & 4 & 8 \\
\hline $\mathrm{B} /$ ventura & 561 & 7 & 3 & 0 & 0 & 0 & 0 & 0 \\
\hline Palmira & 3957 & 18 & 33 & 0 & 0 & 135 & 1 & 4 \\
\hline Buga & 3117 & 19 & 19 & 2 & 0 & 376 & 1 & 4 \\
\hline Tulua & 3284 & 14 & 20 & 8 & 0 & 85 & 1 & 2 \\
\hline Roldanillo & 3679 & 20 & 22 & 3 & 0 & 46 & 1 & 0 \\
\hline Cartago & 2725 & 9 & 21 & 1 & 0 & 302 & 2 & 0 \\
\hline Total & 24017 & 118 & 146 & 21 & 7 & 1871 & 10 & 18 \\
\hline
\end{tabular}

Fuente: Elaboración de la autora a partir de Resumen de movimiento de población del Departamento en el decurso de 1912 a 1916. Roberto Zawadzky, Boletín de Estadística. 1: 1. Cali: Imprenta del Pacífico, 1917: 56-57.

La mayoría de las escuelas se encontraban divididas por nivel educativo en primaria y secundaria; a su vez, éstas se clasificaban por género. En 1916 existían matriculados 11.455 varones y 12.562 mujeres en el área de primaria; por su parte, la secundaria presentaba un panorama mucho más bajo de inscripción donde solo existían 968 varones y 903 mujeres registrados en las diferentes escuelas. Como se observa, el número de alumnos asentados para la secundaria solo era del 7,8\% con relación a la primaria, si esto se compara con el número total de habitantes para la época, solo hacían parte del proceso educativo el 8,63\% de la población total. Este panorama se debía en gran parte a la falta de mano de obra existente en la región, siendo más rentable para las familias campesinas hacer uso de sus niños y jóvenes en las labores del campo que enviarlos a la escuela.

El departamento del Valle del Cauca, sin embargo, tenía el propósito de afianzar su aparato educativo y brindar recursos para este proceso. Para esta tarea se destinó una importante suma de capital, invertida en la construcción de edificios, el pago de sueldos de maestros, arrendamiento de locales, mobiliario y alumbrado, siendo estos recursos necesarios para el desarrollo de la educación y el buen funcionamiento de las escuelas urbanas y rurales. Este interés propio de los gobernantes locales, permitió pensarse la necesidad de ampliar el sistema educativo al mayor número de pobladores, considerando esto un camino expedito para alcanzar el progreso ${ }^{46}$. Para tal fin el departamento destinó 173.387,94 pesos en el año de 1916, aumentando este rubro en comparación los años in-

\footnotetext{
46 Maritza Guachetá, "Historia de la educación pública en el Valle del Cauca”; Néstor Valencia Llano, “Concepción e impacto social de la Facultad de Ciencias Agropecuarias en la Universidad Nacional de Colombia - Sede Palmira y estrategias para optimizar su proyección comunitaria desde la Educación Social" (Tesis de Doctorado en Historia, Universidad de Granada, 2012).
} 
mediatamente anteriores en 37.735 pesos $^{47}$. Si se cotejan estos recursos con otras regiones del país, observamos que el Valle del Cauca fue uno de los territorios en los que mayor inversión existió en educación, con el propósito de alcanzar mejor cobertura, calidad y preparación de los instructores ${ }^{48}$. Este objetivo motivó a los dirigentes a apoyar la "Ley Uribe” de 1903 y el Decreto Reglamentario 491 de 1904 que logró, para la segunda década del siglo XX, un nivel de alfabetización superior al resto de la nación. Este panorama ayudó a concentrar las actividades comerciales, industriales y financieras existentes en el país, gozando de una posición privilegiada y una expansión económica, territorial y poblacional al igual que los departamentos de Caldas, Atlántico, Antioquia, Meta y las islas de San Andrés y Providencia ${ }^{49}$.

\section{Ocupación}

Era lógico que la población del departamento del Valle del Cauca, que se destacaba como una región principalmente agrícola y comercial, se ocupara en gran medida en estos renglones económicos. Es así como se mostró en el Boletín de Estadística de 1917, que clasificó las labores por profesiones en cuatro sectores: científicas, industriales, empleados y artes (Gráfico 5). Discriminando cada una de éstas, se destacó dentro del ramo científico, individuos con título de pregrado como abogados, médicos e ingenieros. Por su parte las profesiones industriales fueron repartidas en cuatro rangos, predominando la población dedicada a la explotación de la tierra, seguida de los ganaderos, comerciantes e industriales. En el campo de empleados, dependiente de un salario, se denotan, los funcionarios al servicio de la región, como los policías, militares y funcionarios administrativo del gobierno local, siendo estos menos de 2000, imperando los empleados particulares con 168.688 individuos. Por último, en la sección artesanos se estableció la existencia de 30.118 sujetos, distribuidos en las categorías de albañil, carpintero, herrero, latonero, sastre, talabartero, zapateros y otros ${ }^{50}$.

\footnotetext{
47 Estadística que se obtuvo al analizar el cuadro de estadística Comparativa de los Presupuestos de gastos efectivos del departamento del Valle en los años fiscales de 1912 a 1917. También se pudo calcular que durante este periodo la proporción de gasto anual por habitante correspondió a $\$ 1,51$ oro.

48 María Ramírez y Juana Patricia Téllez, "La educación primaria y secundaria en Colombia, en el siglo XX”, en Economía colombiana del siglo XX: un análisis cuantitativo, edit. James Robinson y Miguel Urrutia (Bogotá: Fondo de Cultura Económica, 2007). 49 Maritza Guachetá, "Historia de la educación pública en el Valle del Cauca”, 41.

50 Dentro del rubro "otro" cabe incluir los siguientes oficios: ebanistas, joyeros, hilanderos, modistas, sombrereros, yeseros y tejedores, que no están explícitos en el censo estadístico analizado en este apartado, pero sí se visualizan en otros datos estadísticos como las defunciones ocurridas, resumen de los nacimientos ocurridos en el Valle del Cauca según la profesión del padre, entre otros.
} 


\section{Gráfico 5. Ocupación de los habitantes por profesión en 1916}

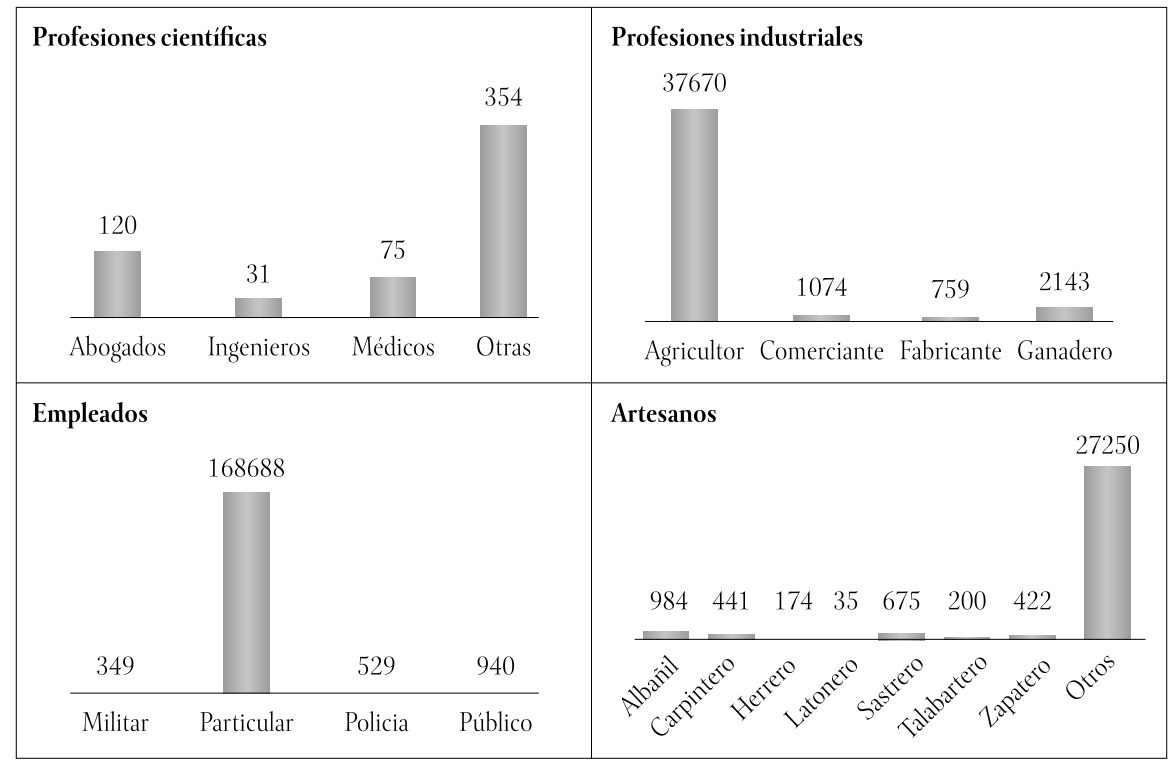

Fuente: Elaboración de la autora a partir de Resumen de movimiento de población del Departamento en el decurso de 1912 a 1916. Roberto Zawadzky, Boletín de Estadística. 1: 1. Cali: Imprenta del Pacífico, 1917: 86.

Las dinámicas profesionales, como señaló el gráfico anterior, permiten inferir que los vallecaucanos se dedicaban en su mayoría a la agricultura y las actividades artesanales, indicando con esto su autonomía, ya fuese en el sector rural, siendo campesinos propietarios de la tierra o artesanos ubicados en las zonas urbanas o prestadores de servicios a un cúmulo de pobladores dependientes de un patrón, en calidad de asalariados, los cuales se ocupaban en otras actividades y oficios como los comerciales, industriales y sectores administrativos ${ }^{51}$. Este conjunto de actividades se relacionaba entre sí, logrando aportar a la movilidad social, económica y política de la región.

\section{Consideraciones finales}

La creación del Valle del Cauca en el año de 1910 trajo nuevos retos a los dirigentes y al aparato burocrático que llevaría sus riendas. En las anteriores líneas se quiso mostrar, a partir del análisis del Boletín de Estadística del año de 1917, varios aspectos del estado del Valle del Cauca hacia finales de la segunda década del siglo XX. Primero que todo, el uso e interés por parte de los gobernantes de la estadística para trazar políticas públicas. Las cifras posibilitan advertir una temprana organización

51 Eduardo Mejía, Origen del campesinado vallecaucano (Cali: Universidad del Valle, 1993); Jaime Eduardo Londoño Motta, "Path dependence, instituciones y ordenanzas". 
administrativa por parte de los entes a la cabeza del gobierno regional, ligada al progreso, como ellos lo llamaban. Es decir, estos burócratas y políticos locales, se apropiaron concienzudamente el discurso de modernización que se respiraba en la época.

La estadística recolectada dio cuenta de un universo particular de cambio, en momentos en los cuales el país se insertaba de manera contundente a la economía mundial. Estas cifras ayudaron, además, a visualizar el crecimiento paulatino entre los sectores pecuarios, comerciales y fabriles y el incremento poblacional en la región. De igual manera, se denota el interés por invertir e incentivar entre los agricultores y empresarios la apertura agrícola con la promulgación de cultivos como el cacao, la caña de azúcar y el maíz.

Este artículo, si bien muestra un panorama general, permite afirmar que no hubo un solo aspecto de la vida económica, política y social de los habitantes del Valle del Cauca que no quedaran consignados en el Boletín de Estadística. En sus páginas también aparecen censos como el poblacional y agrícola, inscribiéndose éstos en las políticas estatales promovidas por el gobierno nacional, con las que se buscaba compilar estadística básica del territorio nacional con el ánimo de mejorar la administración pública. Es también importante señalar la contribución y rol de personajes a nivel local, aportando al departamento en la primera mitad de siglo una de las mejores oficinas de estadística y que el Boletín de Estadística se convirtiera, de la mano de Roberto Zawadzky, en la mejor muestra de un fenómeno al menos interesante: las complejas relaciones entre la estadística moderna, la administración pública y el progreso.

\section{Referencias bibliográficas}

\section{Fuentes primarias/documentales}

Robles, Manuel F., Ley 4 de 1913 sobre régimen político y municipal. (Bogotá: Casa editorial América, 1920).

Zawadzky, Roberto, Boletín Estadístico del Valle del Cauca, Vol. I: No. 1. (Cali: Imprenta del Pacifico, 1917).

\section{Bibliografía consultada}

Almario, Oscar Almario. La configuración del Valle del Cauca, Colombia, 1850-1940. Espacio, poblamiento, poder y cultura. Cali: Cecan, 1994.

Arroyo, Jairo Henry. Historia de las prácticas empresariales en el Valle del Cauca. Cali: Universidad del Valle, 2006.

Bejarano, Jesús. "El despegue cafetero. 1900-1928", en Historia económica de Colombia., editado por José A. Ocampo. Bogotá: Siglo XXI, 1987. 
Calera, Marcela. "Historia de los precios de los alimentos en Cali según el diario El Relator, 1919-1950”. Tesis de pregrado, Universidad del Valle, 2013.

Flórez-Malagón, Alberto. El poder de la carne. Historia de ganaderías en la primera mitad del siglo XX en Colombia. Bogotá: Universidad Javeriana: 2008.

Guachetá, Maritza. "Historia de la educación pública en el Valle del Cauca 1912-1915: Instrucción primaria y secundaria”. Tesis de pregrado, Universidad del Valle, 2013.

Hurtado, Aura. "Opinión pública y formación del departamento del Valle, 1903-1910”, CS 7 (2011): 161 - 192. DOI: http://dx.doi.org/10.18046/recs.i7.1041

Kalmanovitz, Salomón y López, Enrique, La agricultura colombiana en el siglo XX. Bogotá: Fondo de cultura económica, 2006.

Kalmanovitz, Salomón, “Colombia en las dos fases de globalización”, en Revista de Economía Institucional, 9: 17 (2007): 43-74.

Londoño Motta, Jaime Eduardo. "Path dependence, instituciones y ordenanzas en la configuración del departamento del Valle, 1910-1949”, CS 8 (2011): 279-314. DOI: http:// dx.doi.org/10.18046/recs.i8.1136

Mejía, Eduardo, Origen del campesinado vallecaucano. Cali: Universidad del Valle, 1993.

Ocampo, José Antonio, "El surgimiento de Cali como centro industrial”, en José Antonio Ocampo y Santiago Montenegro, editores, Crisis mundial, protección e industrialización. Bogotá: Grupo editorial Norma, 2007.

Ordóñez, Luis. Industrias y empresarios pioneros: Cali 1910-1945. Cali: Universidad del Valle, 1998.

Ramírez, Carlos, “El camino férreo del Pacífico 1862-1915”. Tesis de pregrado, Universidad del Valle, 2009.

Ramírez, María y Téllez, Juana Patricia, "La educación primaria y secundaria en Colombia, en el siglo XX”, en Economía colombiana del siglo XX: un análisis cuantitativo, edits. James Robinson y Miguel Urrutia. Bogotá: Fondo de Cultura Económica, 2007.

Rodríguez Caporali, Enrique. "La burocratización incipiente: la administración pública en Cali entre 1910 y 1940", en Formas de modernización regional en el Suroccidente Colombiano. Cali: Universidad Icesi, 2013, 45-90.

Rodríguez Caporali, Enrique, "Ciudadanos y amigos: relaciones sociales y políticas en Cali, 1906-1930", en Historia de Cali, Siglo XX. Tomo II, Política, edit. Gilberto Loaiza. Cali: Universidad del Valle, 2012.

Sáenz, José Darío, “La formación de la burocracia en el Valle del Cauca entre 1910 y 1950 ”, en Formas de modernización regional en el Suroccidente Colombiano. Cali: Universidad Icesi, 2013, 91-140.

Santos Delgado, Adriana y Sánchez Mejía, Hugues, "Estado, innovación y expansión de la agroindustria azucarera en el valle del río Cauca (Colombia), 1910-1945”, en Revista América Latina en la Historia Económica. 21: 3 (2014): 201-230. DOI: http://dx.doi.org/10.18232/ alhe.v21i3.583 
Santos Delgado, Adriana y Sánchez Mejía, Hugues. La irrupción del capitalismo agrario en el Valle del Cauca: políticas estatales, trabajo y tecnología, 1900-1950. Cali: Universidad del Valle, 2010 .

Valencia Llanos, Albeiro, Colonización, fundaciones y conflictos agrarios. (Gran Caldas y Norte del Valle).Manizales: Artes gráficas Tizan: 2000.

Valencia Llanos, Alonso, Empresarios y políticos en el estado soberano del Cauca. Cali: Universidad del Valle: 1993.

Valencia Llano, Néstor, "Concepción e impacto social de la Facultad de Ciencias Agropecuarias en la Universidad Nacional de Colombia - Sede Palmira y estrategias para optimizar su proyección comunitaria desde la Educación Social". Tesis de Doctorado en Historia, Universidad de Granada, 2012.

Valdivia, Luis, Economía y espacio en el Valle del Cauca 1850-1950. Cali: Universidad del Valle, 1992. 